Supporting Information for

\title{
Pore Characterization and Inner Adsorption Mechanism Investigation for Methane in Organic and Inorganic Matters of Shale
}

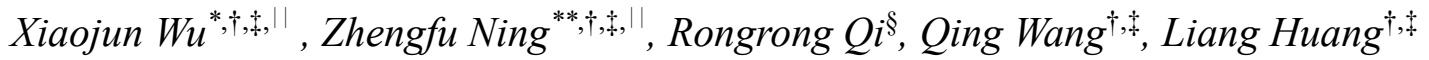

\author{
†State Key Laboratory of Petroleum Resources and Prospecting, China University of Petroleum \\ (Beijing), 18 Fuxue Road, Changping, Beijing 102249, P. R. China \\ $\ddagger$ Department of Petroleum Engineering, China University of Petroleum (Beijing), 18 Fuxue \\ Road, Changping, Beijing 102249, P.R. China \\ $\S$ Guangzhou Marine Geological Survey, Guangzhou 510760, P.R. China
}

Corresponding author. 1. Email: xiaojun_wu@outlook.com (Xiaojun Wu)

Tel: $86-10-8973-2318$

2. Email: nzf@cup.edu.cn (Zhengfu Ning)

Tel: 86-10-8973-2198 


\section{S.1. The Adsorption Isotherm Curves of $\mathrm{CO}_{2}$}

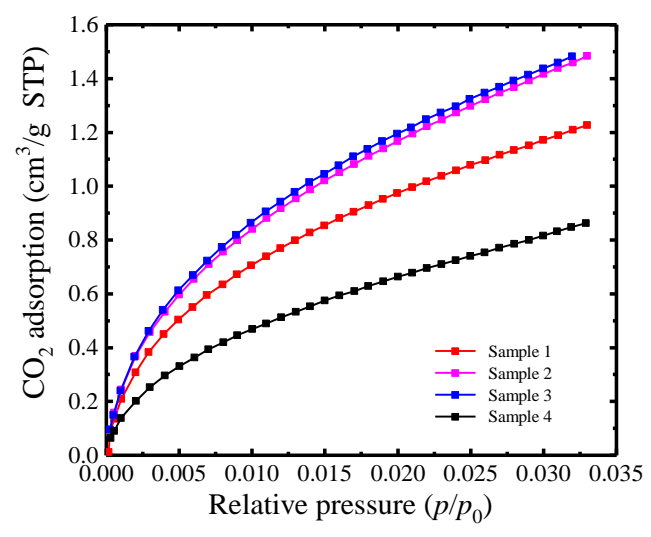

Figure. S-1. The adsorption isotherm curves of $\mathrm{CO}_{2}$ for samples $1-4$ at $273 \mathrm{~K}$. The parameter $p_{0}$ is the saturated vapor pressure. STP is the abbreviation of standard temperature and pressure.

\section{S.2. Expressions for SLD Model}

As shown in Figure S-2, the methane molecule exists in the slit-like pore with $L$ width. The width, $L$, is corresponding to the APD of the experimental sample. The position of the particular methane molecule is marked as $z$, which is the distance to one of the walls. The distance of this methane molecule to another wall is $L-z$. 


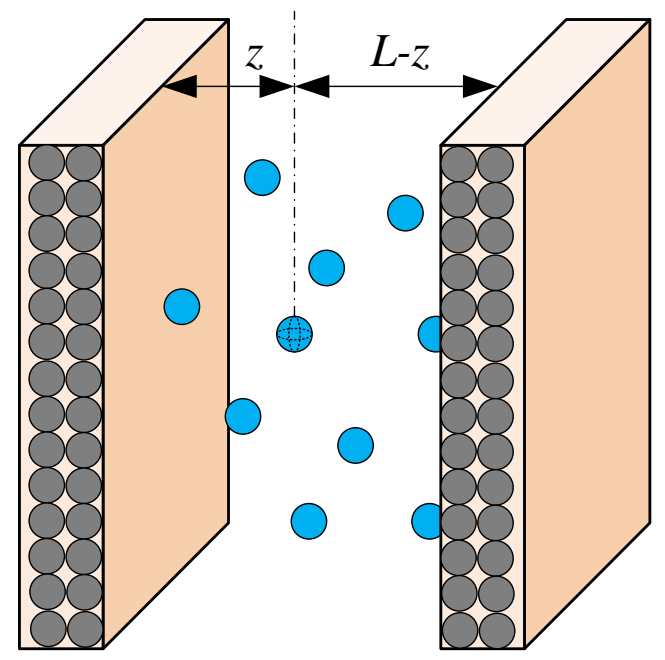

Figure. S-2 The positions of methane molecules in the slit-like solid wall. The blue circle represents a methane molecule. The dark grey circle represents solid atom, comprising the sold wall, which is yellow in the figure.

Eq. S1 could be given below for the adsorption density of methane at position $z$. This equation was also given in previous research ${ }^{1}$. This equation is the combination of the Peng-Robinson equation of state (PR EOS) ${ }^{2}$, and Lennard-Jones (L-J) fluid-wall interaction potential ${ }^{3}$.

$$
\begin{aligned}
& \frac{b_{\mathrm{ads}} \rho(z)}{1-b_{\mathrm{ads}} \rho(z)}-\frac{a(z) \rho(z)}{\mathrm{R} T\left(1+2 \rho(z) b_{\mathrm{ads}}-\rho^{2}(z) b_{\mathrm{ads}}^{2}\right)}- \\
& \ln \left[\frac{p\left(1-b_{\mathrm{ads}} \rho(z)\right)}{\mathrm{R} T \rho(z)}\right]-\frac{a(z)}{2 \sqrt{2} b_{\mathrm{ads}} \mathrm{R} T} \ln \left[\frac{1+(1+\sqrt{2}) b_{\mathrm{ads}} \rho(z)}{1+(1-\sqrt{2}) b_{\mathrm{ads}} \rho(z)}\right]- \\
& \left\{\frac{b \rho_{\mathrm{b}}}{1-b \rho_{\mathrm{b}}}-\frac{a_{\mathrm{b}} \rho_{\mathrm{b}}}{\mathrm{R} T\left(1+2 \rho_{\mathrm{b}} b-\rho_{\mathrm{b}}^{2} b^{2}\right)}-\ln \left[\frac{p\left(1-b \rho_{\mathrm{b}}\right)}{\mathrm{R} T \rho_{\mathrm{b}}}\right]-\frac{a_{\mathrm{b}}}{2 \sqrt{2} b \mathrm{R} T} \ln \left[\frac{1+(1+\sqrt{2}) b \rho_{\mathrm{b}}}{1+(1-\sqrt{2}) b \rho_{\mathrm{b}}}\right]\right\} \\
& =-\frac{N_{\mathrm{A}}}{\mathrm{R} T}[\Psi(z)+\Psi(L-z)]
\end{aligned}
$$

In Eq. S1, $\Psi(z)$ is the interaction potential with the left-side wall, and $\Psi(L-z)$ is the interaction potential with the right-side wall. 
By integrating of adsorbed density of methane at different positions, the excess adsorption of methane on the whole pore could be acquired ${ }^{4,5}$.

$$
n^{\mathrm{ex}}=\frac{A}{2} \int_{\frac{3}{8}}^{L-\frac{3}{8} \sigma_{\mathrm{fff}}} \sigma_{\mathrm{ff}}\left(\rho(z)-\rho_{\mathrm{b}}\right) \mathrm{d} \mathrm{z}
$$

The corrected attractive parameter, $a(z)$, was expressed in the research of Chen et ll. $^{6}$.The other expressions for related fluid-fluid interaction parameters are given below.

$$
\begin{gathered}
a_{\mathrm{b}}=\frac{0.457535 \alpha(T) \mathrm{R}^{2} T_{\mathrm{c}}^{2}}{p_{\mathrm{c}}^{2}} \\
\alpha(T)=\exp \left[( 2 . 0 + 0 . 8 1 4 5 ( T / T _ { \mathrm { c } } ) ) \left(1-\left(T / T_{\mathrm{c}}\right)^{\left.\left.0.134+0.508 \omega-0.0467 \omega^{2}\right)\right]}\right.\right. \\
b=\frac{0.077796 \mathrm{R} T_{\mathrm{c}}}{p_{\mathrm{c}}} \\
b_{\mathrm{ads}}=b\left(1+\Lambda_{\mathrm{b}}\right)
\end{gathered}
$$

Where, the values of $T_{\mathrm{c}}, p_{\mathrm{c}}$ and $\omega$ are from the research of Young et al. ${ }^{7}$

The expressions for related fluid-wall interaction parameters are given below, based on the L-J 10-4

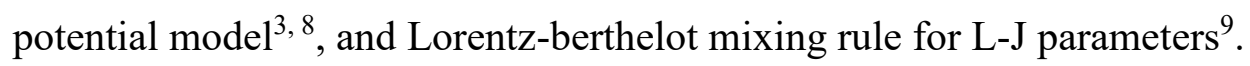

$$
\begin{gathered}
\Psi(z)=4 \pi \rho_{\mathrm{A}} \varepsilon_{\mathrm{fs}} \sigma_{\mathrm{fs}}^{2}\left[\frac{\sigma_{\mathrm{fs}}^{10}}{5\left(z+\sigma_{\mathrm{ss}} / 2\right)^{10}}-\frac{1}{2} \sum_{i=1}^{4}\left(\frac{\sigma_{\mathrm{fs}}^{4}}{\left(z+\sigma_{\mathrm{ss}} / 2+(i-1) \sigma_{\mathrm{ss}}\right)^{4}}\right)\right] \\
\Psi(L-z)=4 \pi \rho_{\mathrm{A}} \varepsilon_{\mathrm{fs}} \sigma_{\mathrm{fs}}^{2}\left[\frac{\sigma_{\mathrm{fs}}^{10}}{5\left(L-z+\sigma_{\mathrm{ss}} / 2\right)^{10}}-\frac{1}{2} \sum_{i=1}^{4}\left(\frac{\sigma_{\mathrm{fs}}^{4}}{\left(L-z+\sigma_{\mathrm{ss}} / 2+(i-1) \sigma_{\mathrm{ss}}\right)^{4}}\right)\right] \\
\left\{\begin{array}{l}
\sigma_{\mathrm{fs}}=\frac{\sigma_{\mathrm{ff}}+\sigma_{\mathrm{ss}}}{2} \\
\varepsilon_{\mathrm{fs}}=\sqrt{\varepsilon_{\mathrm{ss}} \varepsilon_{\mathrm{ff}}}
\end{array}\right.
\end{gathered}
$$

Where, $\varepsilon_{\mathrm{fs}}$ and $\sigma_{\mathrm{fs}}$ are the L-J parameters of fluid-solid, which could be obtained by Lorentz-berthelot mixing rule. The values of $\varepsilon_{\mathrm{ff}}, \varepsilon_{\mathrm{ss}}, \sigma_{\mathrm{ff}}$ and $\sigma_{\mathrm{ss}}$ are from the research of Zhang et al. ${ }^{9}$. 


\section{S.3. Adsorptions for 323.15 and 353.15 K Based on SLD Regression}
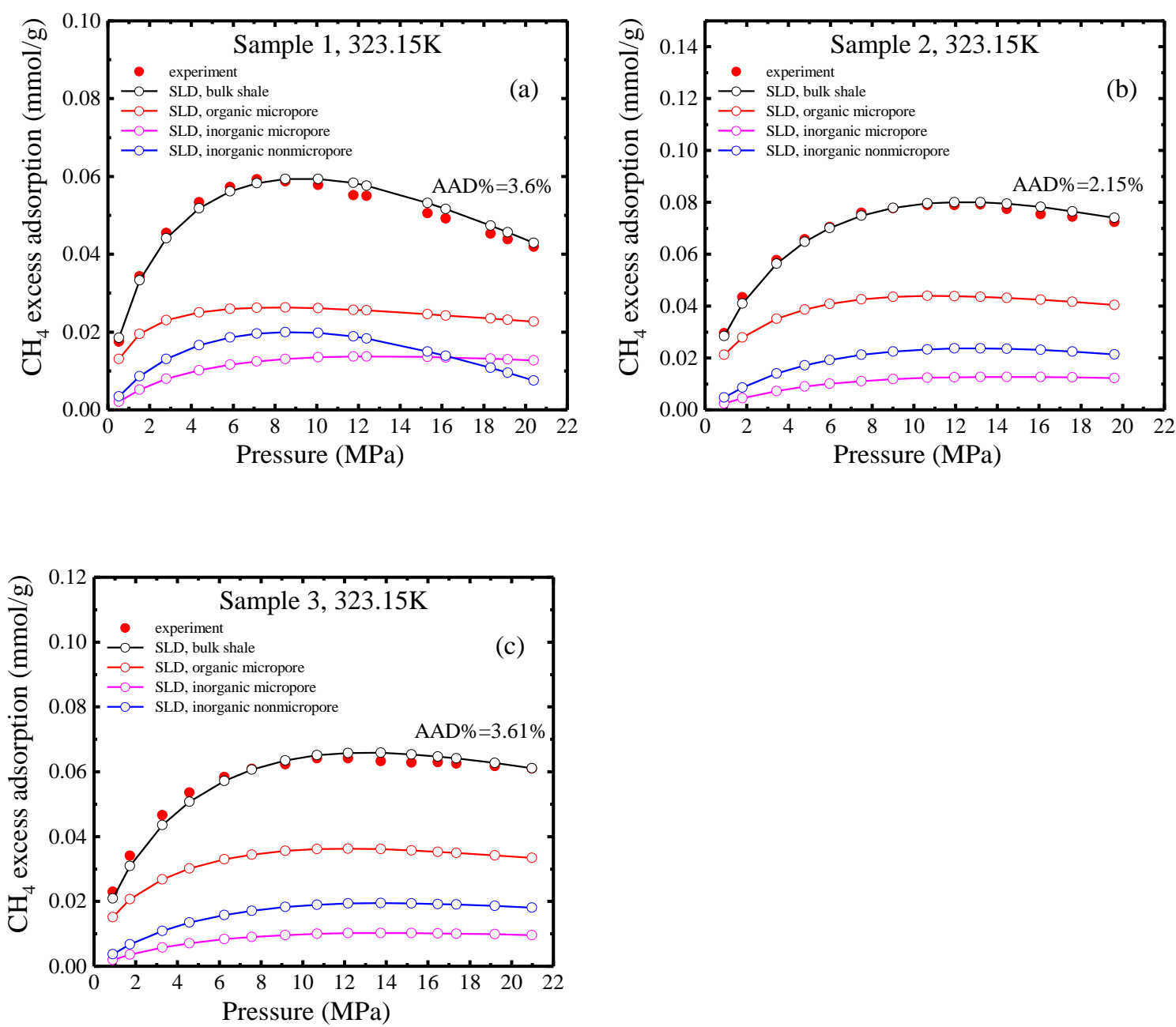

Figure. S-3. SLD regressions for methane excess adsorption isotherms of organic micropores, inorganic micropores and nonmicropores,

and the total pores of bulk gas shale (bulk values), at 323.15K. (a) sample 1, (b) sample 2, and (c) sample 3. 

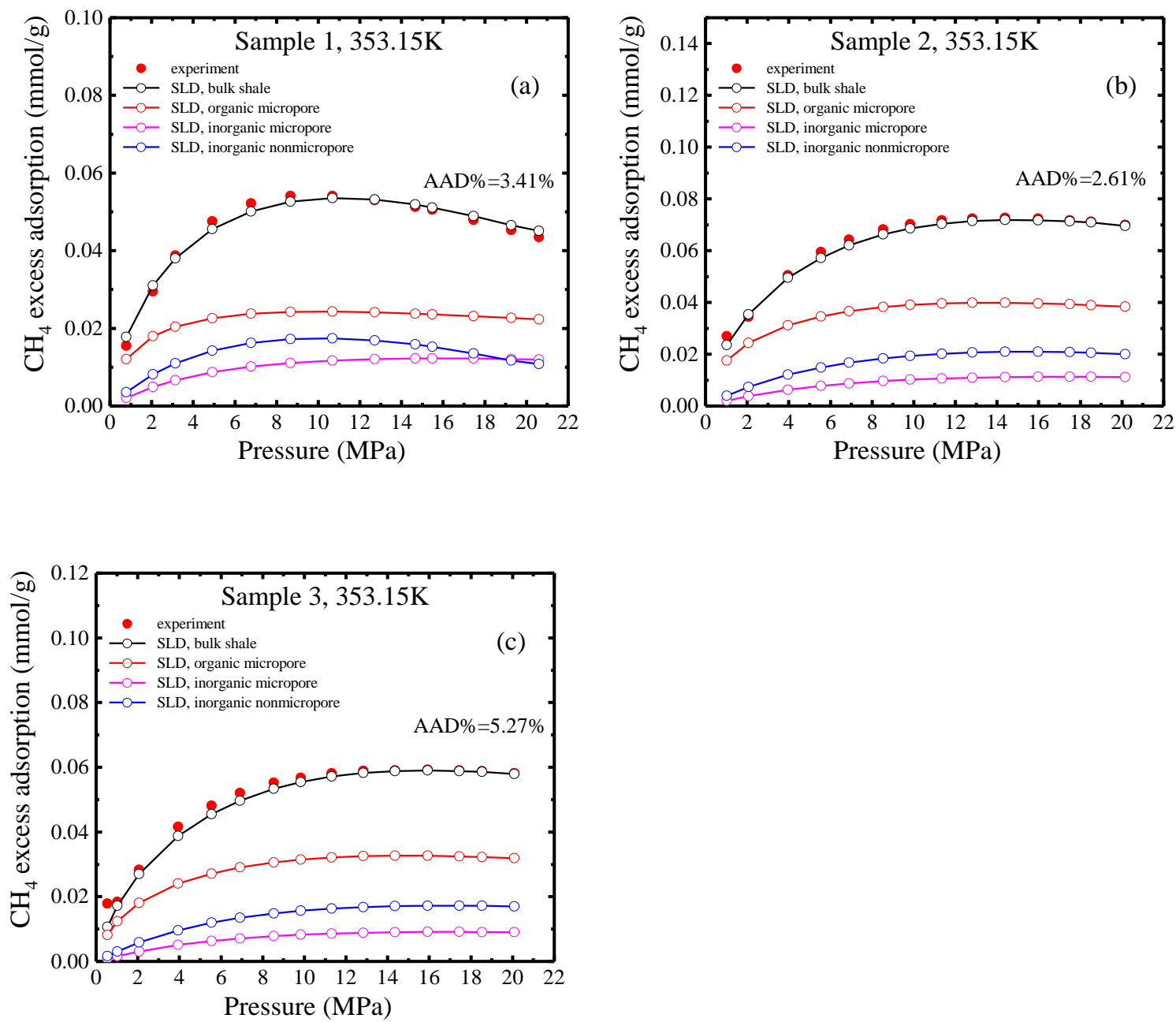

Figure. S-4. SLD regressions for methane excess adsorption isotherms of organic micropores, inorganic micropores and nonmicropores,

and the total pores of bulk gas shale (bulk values), at 353.15K. (a) sample 1, (b) sample 2, and (c) sample 3. 


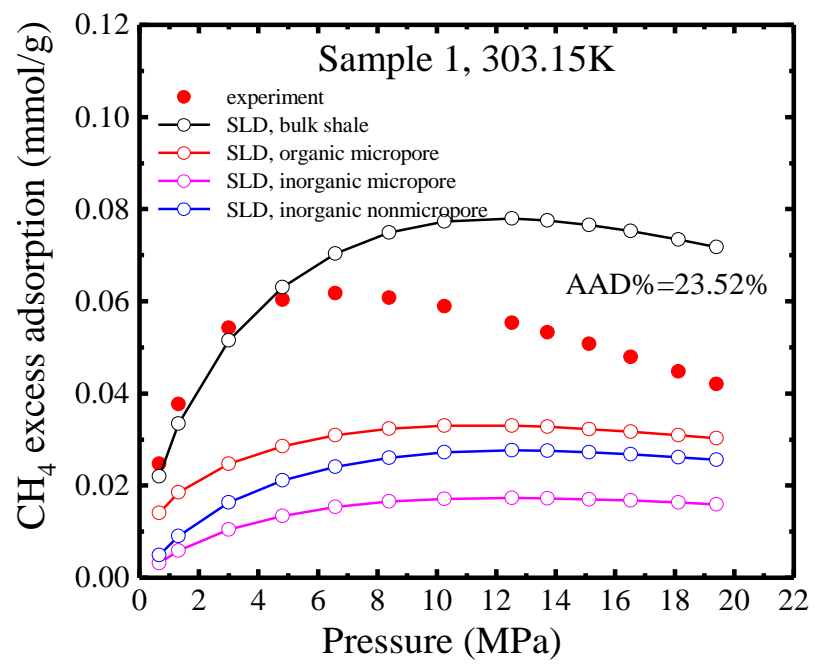

Figure. S-5 SLD simulation for methane adsorption isotherms of the total pores of gas shale sample 1, organic micropores, inorganic micropores and nonmicropores (bulk values), with the initial structure values, at $303.15 \mathrm{~K}$.

\section{S.4. The Effect of Pressure on the Adsorbed Density Distributions in Organic and Inorganic}

\section{Micropores}

In Figure S-6a, among the five given pressures, the excess adsorbed density peak at $4.82 \mathrm{MPa}$ in organic micropores is the largest, while the largest one in inorganic micropores is at $10.26 \mathrm{MPa}$ (Figure S-6c). Then, after reaching the largest values, the excess adsorbed density peaks decrease gradually with pressure in organic and inorganic micropores. This is owing to the impact of bulk density on the excess adsorbed density ${ }^{10}$. The bulk density grows with pressure and leads to the decrease of excess adsorbed density peak. Therefore, at fixed temperature, the excess adsorbed density distribution is the comprehensively determined by pressure and the fluid-wall interaction potential distribution. As shown in Figures S-6b and S-6d, at the same position of all the adsorbed regions, without the consideration of bulk density, the absolute adsorbed densities in organic and inorganic micropores increase monotonically with pressure. Higher pressure leads to a slower 
decrease of absolute adsorbed density with distance (Figures S-6b and S-6d), owing to that more methane molecules exist in the organic or inorganic micropore and are more likely to be adsorbed. In conclusion, in addition to the effect of fluid-wall interaction, the excess and absolute adsorbed density distribution in the pore is controlled by the pressure.
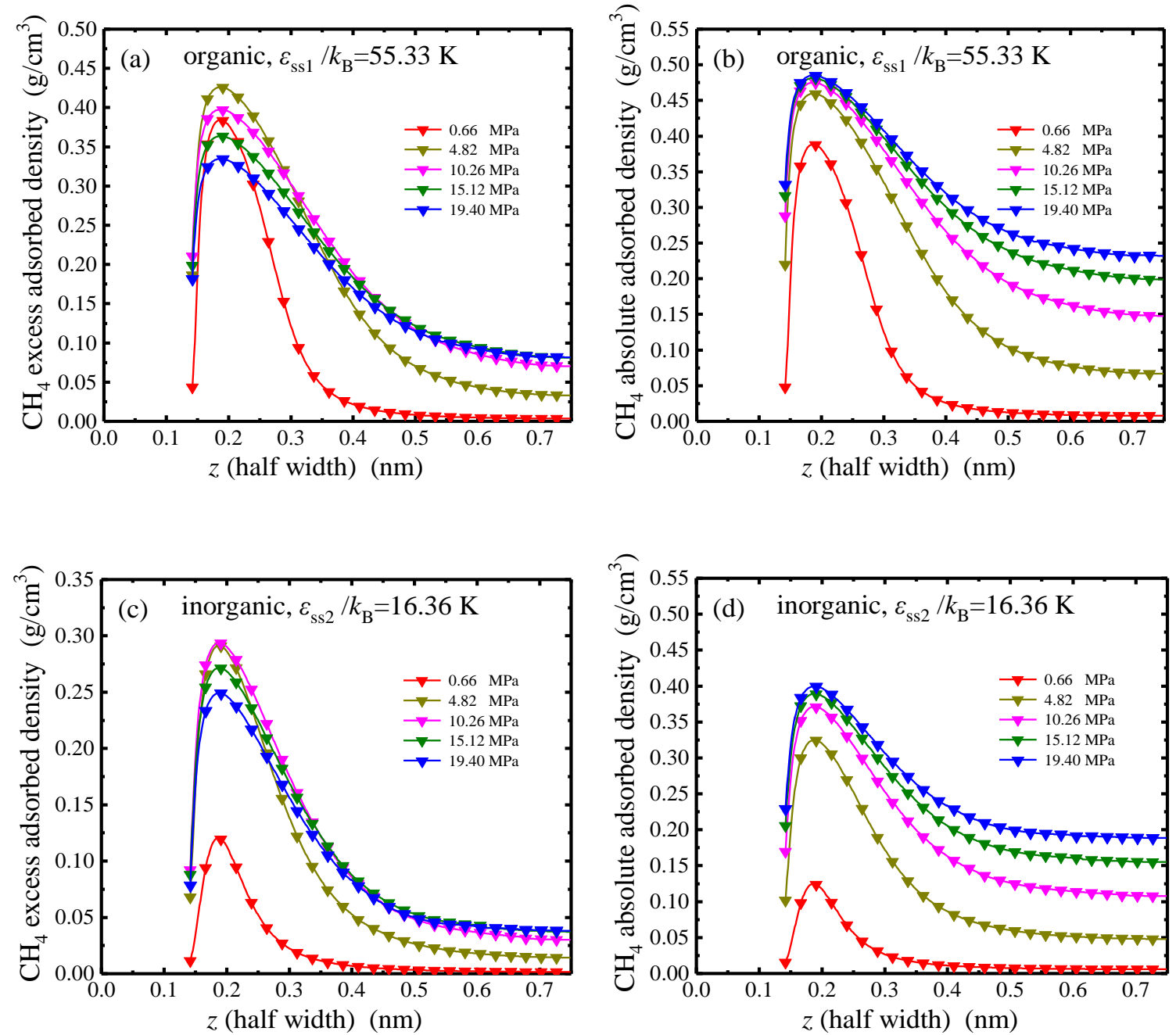

Figure. S-6. The methane excess (a and c) and absolute (b and d) adsorbed density distributions in organic (a and b) and inorganic (c and d) micropores for five different pressures. Half width of pore is shown here due to the symmetry. 


\section{S.5. The Effect of $\varepsilon_{\mathrm{ss}}$ on Methane Adsorption in Organic-inorganic Pores}

For a further investigation of the impact of fluid-wall interaction on the adsorption, based on the same pore structure with Figure $5\left(5 \mathrm{~m}^{2} / \mathrm{g} \mathrm{SSA}\right.$ and $1.5 \mathrm{~nm}$ pore size $)$, at $19.4 \mathrm{MPa}$ and $303.15 \mathrm{~K}$, the excess adsorption simulation was conducted in a range of $\varepsilon_{\mathrm{s} S} / k_{\mathrm{B}}$ (Figure S-7), which is $10-70 \mathrm{~K}$. According to the conclusion above, changing from 10 to $70 \mathrm{~K}$, the $\varepsilon_{\mathrm{ss}} / k_{\mathrm{B}}$ could be the value of the organicinorganic mixture matter from high-purity inorganic matter to organic matter. The $\varepsilon_{\mathrm{ss}}$ value for the organic-inorganic mixture matter could be expressed as,

$$
\varepsilon_{\mathrm{ss}}=\varepsilon_{\mathrm{ss}-\text { organic }} \mathrm{TOC}+\varepsilon_{\mathrm{ss}-\text { inorganic }}(1-\mathrm{TOC})
$$

The $\varepsilon_{\mathrm{ss}}$ increases with the proportion increasing of organic matter for the organic-inorganic mixture pores. The existence of organic-inorganic mixture matter for shale has been proved, by finding of organic matter within the smectite interlayer ${ }^{11}$. Additionally, there is considerable contacting area between organic and inorganic matters ${ }^{12,13}$, and the contacting area may affect the adsorption of bulk shale $^{12}$. Thus, it is necessary to investigate the adsorption of organic-inorganic mixture pore. As shown in Figure $\mathrm{S}-7 \mathrm{a}$, with the $\varepsilon_{\mathrm{sS}} / k_{\mathrm{B}}$ rising, the excess adsorption increases with a gradually decreasing rate. This is the result of the decreasing fluid-wall interaction potential (negative value) with a gradually decreasing rate, shown by the relationship of fluid-wall interaction potential well depth with $\varepsilon_{\mathrm{ss}}$ in Figure S-7b. Corresponding to the fluid-wall interaction, the excess adsorbed density peak increases with a gradually decreasing rate (Figure S-7b). Therefore, the fluid-wall interaction varies a lot for the organic-inorganic mixture pore with different composition ratios, and has vital influence on the adsorption. 

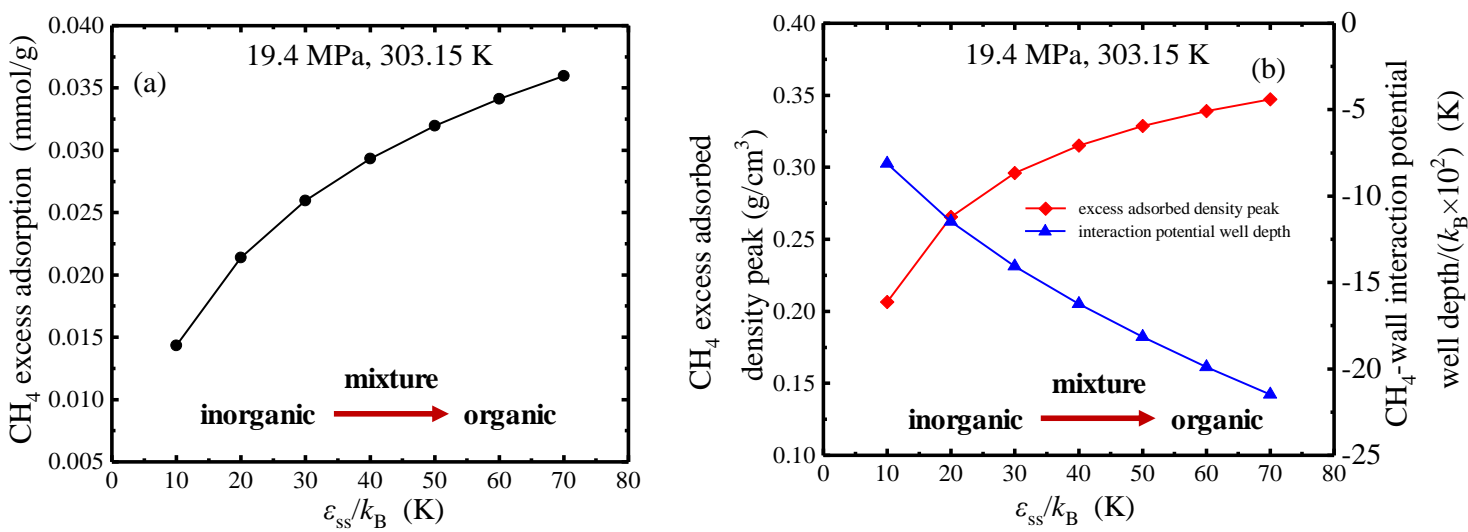

Figure. S-7. The impacts of $\varepsilon_{\mathrm{ss}}$ on methane adsorption at $19.4 \mathrm{MPa}, 303.15 \mathrm{~K}, 5 \mathrm{~m}^{2} / \mathrm{g} \mathrm{SSA}$ and $1.5 \mathrm{~nm}$ pore size conditions. (a) The relationship of methane excess adsorption with $\varepsilon_{\mathrm{ss}}$ (b) The relationship of excess adsorbed density peak with $\varepsilon_{\mathrm{ss}}$, and the relationship of fluid-wall interaction potential well depth with $\varepsilon_{\mathrm{ss}}$. Based on Eq. S10 the rising of $\varepsilon_{\mathrm{ss}}$ represents the growing of TOC.

\section{S.6. The Effects of Organic Micropore Size and Inorganic Nonmicropore Size on Excess}

\section{Adsorption}

For inorganic nonmicropores, the methane excess adsorption decreases gradually with pore size (larger than $3 \mathrm{~nm}$ ) for different pressures (Figure $\mathrm{S}-8 \mathrm{a}$ ), which is consistent with the MS research about the effect of mesopore size on excess adsorption ${ }^{14}$. However, the extent of variation is too small that it is hardly to be observed in Figure S-8a, which was displayed similarly in the DFT research ${ }^{15}$. This could be explained by the given forms of excess adsorption. In the DFT research, in the form of the excess adsorption per unit weight of the adsorbent, the excess adsorption declines slightly with pore size. In the form of the excess adsorption per unit pore volume, the excess adsorption declines rapidly with pore size. As shown in Figure S-8b, in 3, 5 and $7 \mathrm{~nm}$ pores, the fluid-wall interaction potentials are approximatively the same at the same adsorption region, and are all very close to zero 
at the center of the pore. Thus, at fixed pressure, the excess adsorbed density distributions of various pore sizes are approximatively the same at the same adsorbed region, and are all very close to zero at the center of the pore (Figures S-8c and S-8d). This consists with the previous research that the slit pore could be two separate adsorption systems ${ }^{16}$. Therefore, a conclusion could be drawn that, for nonmicropores, the pore size has little effect on the excess adsorption due to the slightly negative connection. This is the reason for that no regression was conducted for the nonmicropore size in the SLD model fitting in Section 3.2.2.
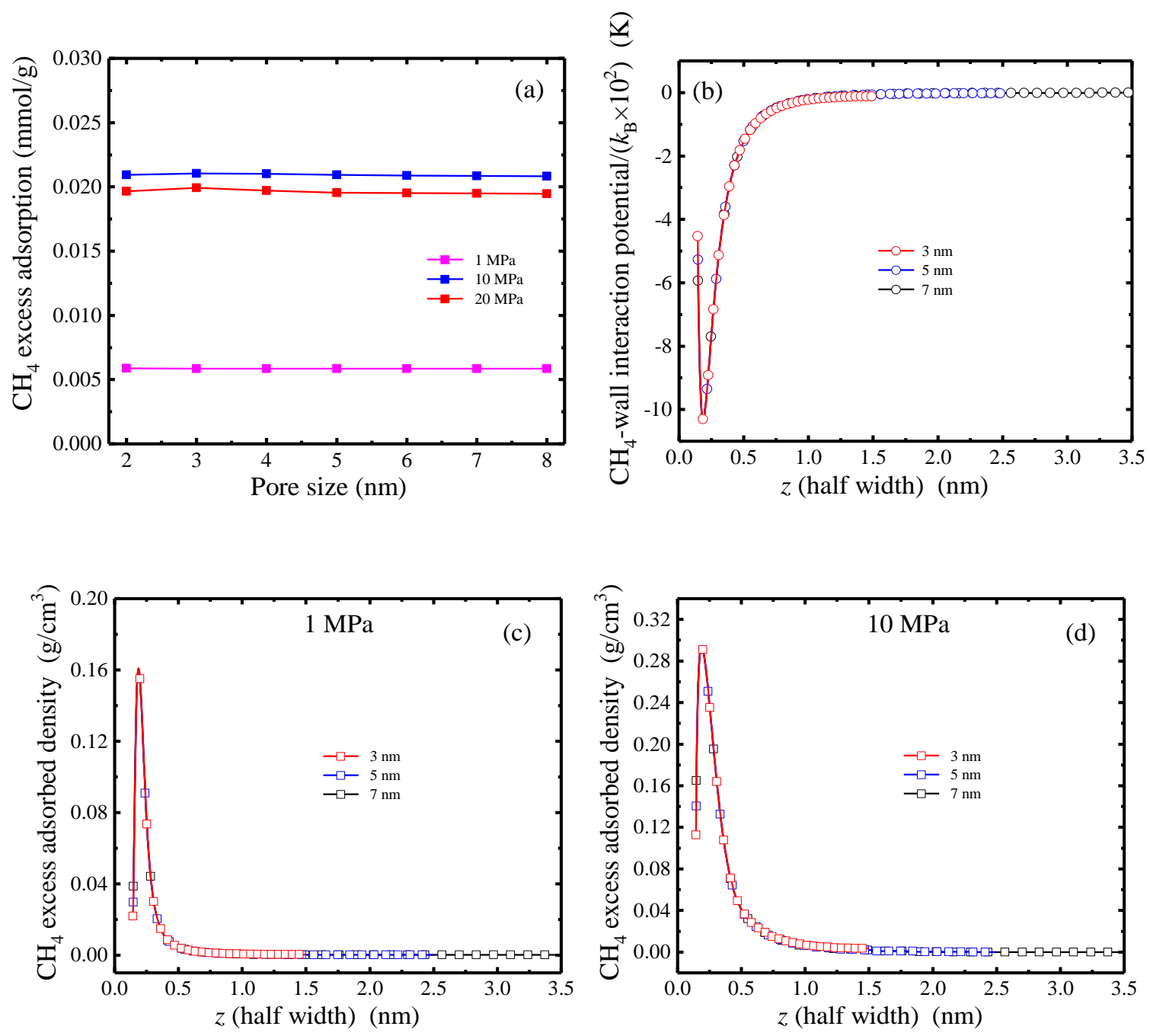

Figure. S-8. The relationship of methane excess adsorption and inorganic nonmicropore size, and the inner adsorptive mechanisms. (a)

The relationships of methane excess adsorption and inorganic micropore size for 1, 10 and $20 \mathrm{MPa}$, at 303.15 K. (b) The fluid-wall 
interaction potential distributions of $1,1.4$, and $2 \mathrm{~nm}$ pore sizes. And the methane excess adsorbed density distributions of $1,1.4$, and $2 \mathrm{~nm}$ pore sizes at (c) $1 \mathrm{MPa}$, and (d) $10 \mathrm{MPa}$. Half width of pore is shown here due to the symmetry.
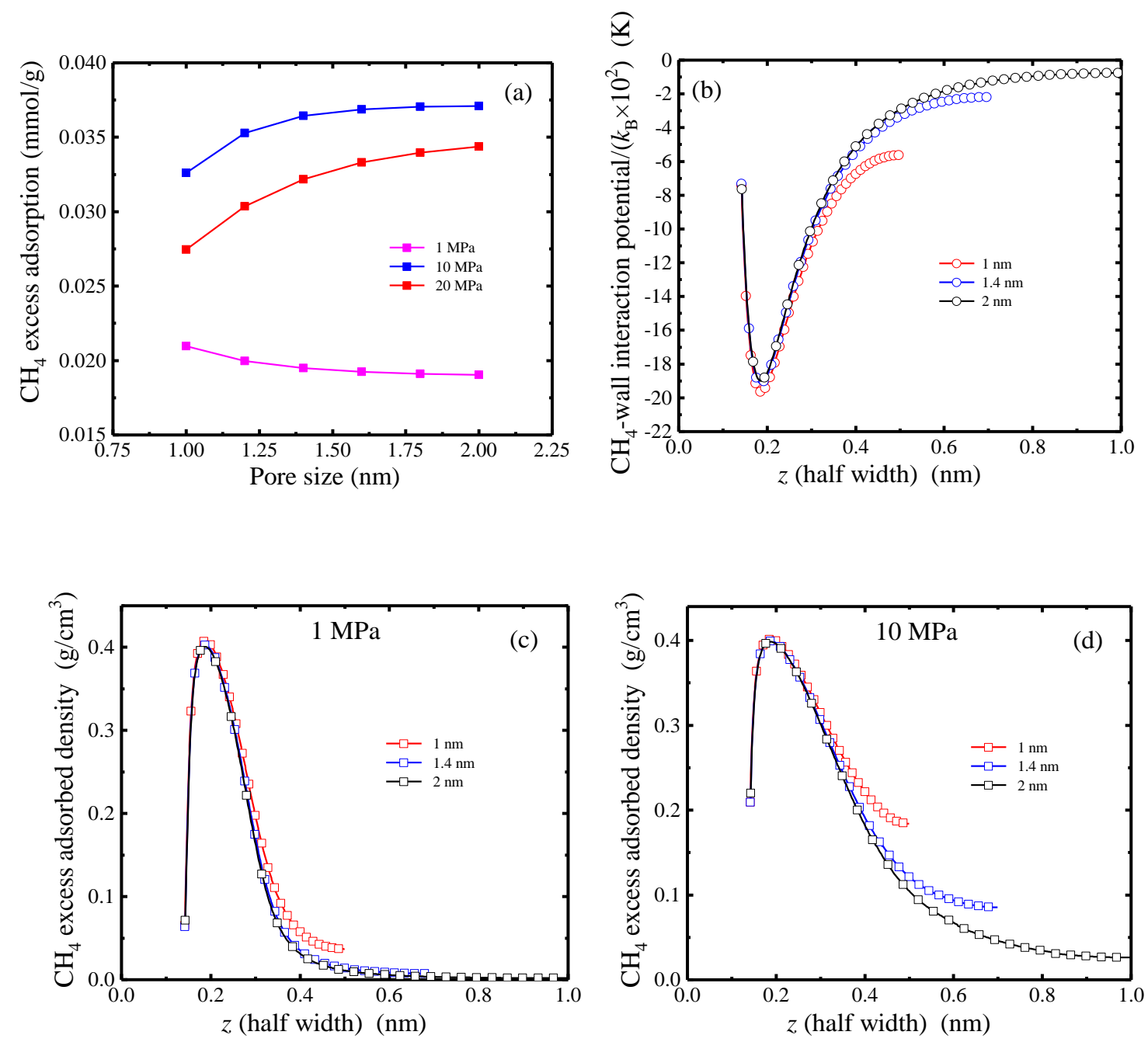

Figure. S-9. The relationship of methane excess adsorption and organic micropore size, and the inner mechanism. (a) The relationships of methane excess adsorption and organic micropore size at 1,10 and $20 \mathrm{MPa}$, and $303.15 \mathrm{~K}$. (b) The fluid-wall interaction potential distributions of 1, 1.4, and $2 \mathrm{~nm}$ pore sizes. And the methane excess adsorbed density distributions of 1, 1.4, and $2 \mathrm{~nm}$ pore sizes at (c) $1 \mathrm{MPa}$, and (d) $10 \mathrm{MPa}$. Half width of pore is shown here due to the symmetry.

\section{S.7. The Nomenclature and Abbreviation}




\begin{tabular}{|c|c|c|c|}
\hline$L$ & Width of slit-like pore, $\mathrm{nm}$ & $n^{e x}$ & Excess adsorption of methane, $\mathrm{mmol} / \mathrm{g}$ \\
\hline$z$ & Distance of molecule to the pore wall, $\mathrm{nm}$ & $A$ & SSA of pore, $\mathrm{m}^{2} / \mathrm{g}$ \\
\hline$a_{\mathrm{b}}$ & Bulk attractive parameter, dimensionless & $T_{c}$ & Critical temperature of methane, $190.56 \mathrm{~K}$ \\
\hline$a(z)$ & $\begin{array}{l}\text { Corrected attractive parameter, } \\
\text { dimensionless }\end{array}$ & $p_{c}$ & Critical pressure of methane, $4.599 \mathrm{MPa}$ \\
\hline$b$ & Bulk repulsive parameter, dimensionless & $\omega$ & Acentric factor, dimensionless \\
\hline$b_{\text {ads }}$ & $\begin{array}{l}\text { Corrected repulsive parameter, } \\
\text { dimensionless }\end{array}$ & $\alpha(T)$ & $\begin{array}{l}\text { Function of temperature for PR EOS, } \\
\text { dimensionless }\end{array}$ \\
\hline$\rho \mathrm{b}$ & Bulk fluid density, $\mathrm{mol} / \mathrm{m}^{3}$ & $\Lambda_{\mathrm{b}}$ & $\begin{array}{l}\text { Correction parameter for repulsive } \\
\text { parameter, dimensionless }\end{array}$ \\
\hline$\rho(z)$ & Adsorbed fluid density, $\mathrm{mol} / \mathrm{m}^{3}$ & $\rho_{\mathrm{A}}$ & $\begin{array}{l}\text { Solid-atom density of the wall surface, } 38.2 \\
\text { atoms } / \mathrm{nm}^{2}\end{array}$ \\
\hline $\mathrm{R}$ & Ideal gas constant, $\mathrm{MPa} \cdot \mathrm{m}^{3} /(\mathrm{mol} \cdot \mathrm{K})$ & $\varepsilon \mathrm{ff}$ & $\begin{array}{l}\text { L-J parameter for the fluid-fluid interaction } \\
\text { energy, } \mathrm{J}\end{array}$ \\
\hline$T$ & Temperature of fluid, $\mathrm{K}$ & $\varepsilon_{\mathrm{ss}}$ & $\begin{array}{l}\text { L-J parameter for the solid-solid interaction } \\
\text { energy, J }\end{array}$ \\
\hline$p$ & Pressure of fluid, MPa & $\varepsilon_{\mathrm{fs}}$ & $\begin{array}{l}\text { L-J parameter for the fluid -solid interaction } \\
\text { energy, J }\end{array}$ \\
\hline$N_{A}$ & Avogadro constant & $\sigma_{\mathrm{ff}}$ & $\begin{array}{l}\mathrm{L}-\mathrm{J} \text { parameter for the molecule diameter of } \\
\text { fluid-fluid, } \mathrm{nm}\end{array}$ \\
\hline$k_{\mathrm{B}}$ & Boltzmann constant, $\mathrm{J} / \mathrm{K}$ & $\sigma_{\mathrm{ss}}$ & $\begin{array}{l}\text { L-J parameter for the molecule diameter of } \\
\text { solid-solid, } \mathrm{nm}\end{array}$ \\
\hline$\Psi$ & Fluid-wall interaction potential, J & $\sigma_{\mathrm{fs}}$ & $\begin{array}{l}\mathrm{L}-\mathrm{J} \text { parameter for the molecule diameter of } \\
\text { fluid-solid, } \mathrm{nm}\end{array}$ \\
\hline
\end{tabular}

\begin{tabular}{|llll|}
\hline \multicolumn{2}{|l|}{ Abbreviation } & & \\
SLD & Simplified local density & MS & Molecular simulation \\
SSA & Specific surface area & PV & Pore volume \\
BET & Brunauer-Emmett-Teller & TOC & total organic carbon \\
BJH & Barrett-Joyner-Halenda & GCMC & Grand canonical Monte Carlo \\
D-R & Dubinin-Radushkevich & XRD & X-ray diffraction \\
D-A & Dubinin-Astakhov & TPV & Total PV \\
DFT & Density functional theory & APD & Average pore diameter \\
\hline
\end{tabular}

\section{References}

1. Wu, X.; Ning, Z.; Han, G.; Wang, Q.; Zhong, Z.; Qi, R.; Cheng, Z.; Huang, L., Modified SLD model for coalbed methane adsorption under reservoir conditions. Arabian Journal of Geosciences 2019, 12, (18), 562.

2. Peng, D.-Y.; Robinson, D. B., A new two-constant equation of state. IndustrialEngineering Chemistry Fundamentals 1976, 15, (1), 59-64.

3. Lee, L. L., Molecular Thermodynamics of Nonideal Fluids. Butterworths: 1988; p 61-73.

4. Fitzgerald, J. E.; Robinson, R. L.; Gasem, K. A., Modeling high-pressure adsorption of gas 
mixtures on activated carbon and coal using a simplified local-density model. Langmuir 2006, 22 , (23), 9610-9618.

5. Chareonsuppanimit, P.; Mohammad, S. A.; Robinson Jr, R. L.; Gasem, K. A., High-pressure adsorption of gases on shales: Measurements and modeling. International Journal of Coal Geology 2012, 95, 34-46.

6. Chen, J. H.; Wong, D. S. H.; Tan, C. S.; Subramanian, R.; Lira, C. T.; Orth, M., Adsorption and desorption of carbon dioxide onto and from activated carbon at high pressures. Industrial \& engineering chemistry research 1997, 36, (7), 2808-2815.

7. Young, A. F.; Pessoa, F. L.; Ahón, V. R., Comparison of 20 Alpha Functions Applied in the PengRobinson Equation of State for Vapor Pressure Estimation. Industrial \& Engineering Chemistry Research 2016, 55, (22), 6506-6516.

8. Mohammad, S. A.; Chen, J. S.; Robinson Jr, R. L.; Gasem, K. A., Generalized simplified localdensity/peng - robinson model for adsorption of pure and mixed gases on coals. Energy \& Fuels 2009, 23, (12), 6259-6271.

9. Zhang, Z.-Y.; Liu, X.-H.; Li, H., The grand canonical Monte Carlo simulation of hydrogen adsorption in single-walled carbon nanotubes. International Journal of Hydrogen Energy 2017, 42, (7), 4252-4258.

10. Wu, X.-J.; Ning, Z.-F.; Cheng, Z.-L.; Wang, Q.; Qi, R.-R.; Huang, L.; Zhang, W.-T., Simplified local density model for gas adsorption in cylindrical carbon pores. Applied Surface Science 2019.

11. Kennedy, M. J.; Pevear, D. R.; Hill, R. J., Mineral surface control of organic carbon in black shale. Science 2002, 295, (5555), 657-660.

12. Rexer, T. F.; Mathia, E. J.; Aplin, A. C.; Thomas, K. M., High-pressure methane adsorption and characterization of pores in Posidonia shales and isolated kerogens. Energy \& Fuels 2014, 28, (5), 2886-2901.

13. Rahman, H. M.; Kennedy, M.; Löhr, S.; Dewhurst, D. N., Clay-organic association as a control on hydrocarbon generation in shale. Organic geochemistry 2017, 105, 42-55.

14. Xiong, J.; Liu, X.; Liang, L.; Zeng, Q., Adsorption of methane in organic-rich shale nanopores: An experimental and molecular simulation study. Fuel 2017, 200, 299-315.

15. Tanaka, H.; El-Merraoui, M.; Steele, W. A.; Kaneko, K., Methane adsorption on single-walled carbon nanotube: a density functional theory model. Chemical Physics Letters 2002, 352, (5-6), 334341.

16. Wu, H. A.; Chen, J.; Liu, H., Molecular Dynamics Simulations about Adsorption and Displacement of Methane in Carbon Nanochannels. Journal of Physical Chemistry C 2015, 119, (24), 150527003615009 . 